\title{
Papers
}

\section{Women's experiences of and preferences for services after rape in South Africa: interview study}

\author{
N J Christofides, D Muirhead, R K Jewkes, L Penn-Kekana, D N Conco
}

\begin{abstract}
Objectives To describe aspects of delivery of health services after rape, including trade-offs, that would most influence choice of service, and to compare views of patients who had used such services with views of members of the community who may be future users or may have experienced barriers to service use.

Design Discrete choice analysis of stated preferences with interviews. Attributes included travel time to the service, availability of HIV prophylaxis, number of returns to the hospital, medical examination, and counselling skills and attitude of the provider.

Setting One rural and one urban site in South Africa. Participants 319 women: 155 who had been raped and four carers recruited through health facilities and 160 comparable women recruited from the community. Of these, 156 were from an urban site and 163 from a rural site.

Main outcome measures Strength of preferences over a range of attributes through the estimation of a benefit function through random effects probit modelling.

Results Factors such as the availability of prophylactic treatment for HIV infection and having a sensitive healthcare provider who could provide counselling are more important in women's decisions to seek care after rape than the travel time necessary to access those services.

Conclusion Our findings support the need for holistic rape services.
\end{abstract}

\section{Introduction}

Women who have been raped have specific health needs: the prevention of pregnancy, HIV, and other sexually transmitted infections; psychological support; and the management and documentation of injuries. ${ }^{1}$ In South Africa, however, only a small proportion of women who have been raped attend services. ${ }^{2}$ These services are of varied quality, and limited resources mean restricted options for provision. ${ }^{3-5}$ Research conducted in industrialised countries and in South Africa has highlighted how use of health services can be a negative and disempowering experience for rape survivors, ${ }^{4-9}$ and this may partly explain the low levels of use.

In efforts to improve services globally there is a move towards having specialised services with carefully selected, sensitive, trained providers who focus on the holistic care of women who have been raped that includes extensive collection of physical evidence. ${ }^{78}$ The South African National Department of Health has developed a new model of rape care policy and clinical management guidelines ${ }^{10}$ and in the process opened debate about the most appropriate model of care. Garcia-Moreno suggests that patients' experiences need to be taken into account in the design of health services. ${ }^{11}$

Discrete choice analysis of stated preferences measures the preferences of users and potential users over various dimensions of a programme. It has been used in the evaluation of health programmes in many settings. ${ }^{12-15}$ It is founded on the assumption that any service can be described by its attributes and that the preference for one service over another is driven by the degree to which it possesses desirable or undesirable attributes. ${ }^{16}$

We investigated which aspects of health services after rape are most valued by patients to determine what would influence choice of service and the trade-offs that women would be prepared to make between different aspects of service delivery. We compared the views of women who had used services after rape with those of women from the community who may be future users or may have experienced barriers to using such services in the past.

\section{Methods}

The study was conducted in one rural and one urban site in South Africa. The sites were selected because there was infrastructure in place to support the recruitment of patients. The urban site in Cape Town was primarily located at a regional hospital and the surrounding communities. The service for people who had been raped was established by the department of justice and is located at the hospital. There is a full time nurse who is primarily responsible for follow-up visits. Any available emergency department physician carries out examinations. The rural site, a district level hospital, was located in the far north of the country and serves the town of Thohoyandou and the surrounding rural area. A non-governmental organisation has established a trauma centre at the hospital to deal with sex based violence and provides support and counselling. Any doctor at the hospital carried out examinations.

We interviewed 319 women at the two sites between November 2003 and January 2004. In Cape Town we recruited 74 women who had used the service and four carers of patients who were too young or could not to be interviewed due to mental disability. In Thohoyandou we recruited 81 patients. We also interviewed 78 comparable women from the community in Cape Town and 82 in Thohoyandou. They were of similar age (plus or minus 5 years) and lived in the same area (living 10 doors away from each service user). During recruitment no connection was made between the community participant and the service user, in this way confidentiality was maintained. They were selected to determine whether potential service users (including those who may have chosen not to use the service) have different priorities 
from those who actually access services. Women who had survived were approached through the health services over the six months before the survey. The examining doctor or nurse in participating services asked them if they would consent to their details being given to a researcher studying quality of services. Those who agreed gave written consent. At the time of the survey, the women were asked again for consent to participate in the study. Though we did not exclude men who had been raped, none were recruited.

Trained fieldworkers administered the questionnaire through face-to-face interviews in Xhosa, Afrikaans, and Venda. We collected data on sociodemographic characteristics (including socioeconomic status ${ }^{17}$ ), attitudes towards rape services, and discrete choice responses from all participants. Participants who had used health services were asked about the actual management that they received including referrals for counselling, treatment received, side effects experienced (if any), information received on side effects, and number of return visits.

The attributes and levels used in the discrete choice analysis were based on results from focus groups held in different parts of the country, expert inputs, and pertinent policy questions. The box outlines the attributes and their levels. This combination resulted in 1162 possible scenarios, which was reduced to 16 by using a main effects orthogonal fractional factorial design in the SPSS orthoplan procedure. We selected one scenario, with services closely reflecting current levels, as a constant comparator (service A) and then presented 15 choice scenarios between this and service B (table 1 shows an example). We used a pictorial representation of the scenarios to facilitate selection by participants.

We included one scenario with all attributes of equal or inferior levels to check that study participants really understood the exercise and were making deliberate choices. We then excluded from any further analysis the 23 participants who did not select the logically better scenario. We excluded respondents who always selected choice A or B, as well as those who obviously

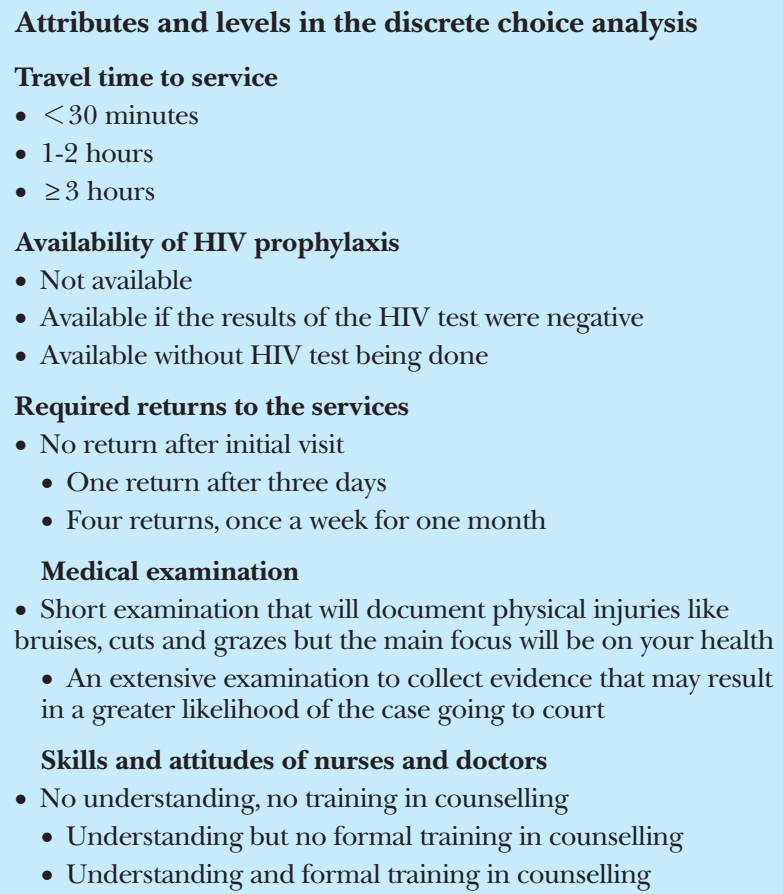

Table 1 Sample of discrete choice analysis item from questionnaire. Participants had to choose service A or service $B^{*}$

\begin{tabular}{lll}
$\begin{array}{l}\text { Choice } \\
\begin{array}{l}\text { Time travelled to } \\
\text { service }\end{array}\end{array}$ & \multicolumn{1}{c}{ Service A } & \multicolumn{1}{c}{ Service B } \\
\hline Medication & $\begin{array}{l}\text { No HIV prevention drugs } \\
\text { available }\end{array}$ & $\begin{array}{l}\text { HIV prevention drugs given } \\
\text { without having to have an HIV } \\
\text { test }\end{array}$ \\
\hline $\begin{array}{l}\text { Required returns to } \\
\text { hospital }\end{array}$ & $\begin{array}{l}\text { Return once only, three days } \\
\text { after your initial visit }\end{array}$ & No return after initial visit \\
\hline $\begin{array}{ll}\text { Medical examination } \\
\text { Short examination that will } \\
\text { document physical injuries like } \\
\text { bruises, cuts, and grazes but } \\
\text { the main focus will be on your } \\
\text { health }\end{array}$ & $\begin{array}{l}\text { Extensive examination of your } \\
\text { private parts to collect evidence } \\
\text { that may result in a greater } \\
\text { likelihood of the case going to } \\
\text { court }\end{array}$ \\
\hline $\begin{array}{l}\text { Skills and attitude of } \\
\text { nurse/doctor }\end{array}$ & $\begin{array}{l}\text { Doctors or nurses who } \\
\text { understand what someone who } \\
\text { has been raped is going } \\
\text { through but are not trained in } \\
\text { counselling }\end{array}$ & $\begin{array}{l}\text { Doctors or nurses have no } \\
\text { training in counselling or } \\
\text { understanding of rape }\end{array}$ \\
\hline
\end{tabular}

*Women chose between service A overall and service B overall, they did this for each scenario. B differed each time and A stayed the same.

failed a test of transitive preferences (which assumes that if bundle $\mathrm{A}$ is preferred to $\mathrm{B}$ and $\mathrm{B}$ is preferred to $\mathrm{C}$ then $\mathrm{A}$ should be preferred to $\mathrm{C})(\mathrm{n}=21)$. Our final analysis included 275 participants ( $86 \%$ of original sample); 135 who had been raped (or a carer responding on behalf of a patient) and 140 community participants; 121 were from Cape Town and 154 were from Thohoyandou.

Data were entered into SPSS 11 (SPSS, Chicago, IL) and analysed in Stata 8.0 (StataCorp, College Station, TX). We used bivariate analysis for social characteristics and health services received by participants. The two sites were compared with $\chi^{2}$ test for categorical variables and a double sided $t$ test for continuous variables.

Because of the multiple response nature of the data we used a random effects probit model to estimate the benefit function of moving from service A to service B. A likelihood test of $r=0$ showed that this was the correct model to use $(\mathrm{P}<0.001)$. We expressed attributes with ordinal or categorical levels as dummy variables (all but number of returns to the service required) as we could not assume linearity, with the benchmark being the level in the comparator scenario (see table 1). Models included variables for the attributes and levels as well as for potential interaction effects with socioeconomic and demographic characteristics and previous service use.

We used likelihood ratio tests to determine coefficients on interaction terms with site, service user, socioeconomic status, and age. Site interactions were significant on all attributes and their inclusion significantly improved the fit of the model $\left(\chi^{2}\right.$ $\mathrm{P}=0.001)$. We estimated separate models for each site as well as the overall to aid in interpretation.

\section{Results}

The median age of the participants was 22 years (range 14.4-66.6 years). Most $(96 \%, \mathrm{n}=150)$ had some schooling (mean 10.2 years). Participants in Thohoyandou were younger, more likely to still be in school, and of lower socioeconomic status (measured by having specific items such as a television in the household, ever going without food, and having worked in the past 12 months) than the women in Cape Town (table 2).

We asked which services the women recruited through health services had received (table 3). Patients in Thohoyandou were significantly more likely to have been referred for counselling. Both sites offered postexposure prophylaxis for HIV, but 
Table 2 Sociodemographic characteristics of total sample (women who had been raped and those recruited from community). Figures are numbers (percentages) of participants unless stated otherwise

\begin{tabular}{lccc} 
& $\begin{array}{c}\text { Cape Town } \\
(\mathbf{n = 1 3 4 )}\end{array}$ & $\begin{array}{c}\text { Thohoyandou } \\
(\mathbf{n = 1 5 9 )}\end{array}$ & $\mathbf{P}$ value* $^{*}$ \\
\hline Mean age (years) & 27.5 & 23.5 & 0.002 \\
\hline Ever attended school & $128(98)$ & $150(96)$ & 0.451 \\
\hline Still in school or college & $41(31)$ & $81(53)$ & $<0.001$ \\
\hline Radio in household & $113(84)$ & $115(75)$ & 0.061 \\
\hline TV in household & $111(82)$ & $85(55)$ & $<0.001$ \\
\hline Car in household & $27(20)$ & $31(20)$ & 0.978 \\
\hline Never goes without food & $82(61)$ & $72(46)$ & $<0.001$ \\
\hline Married or cohabiting & $92(61)$ & $121(78)$ & 0.106 \\
\hline
\end{tabular}

${ }^{*} \mathrm{P}$ value for difference. All tests were $\chi^{2}$ except for mean age, which was $t$ test.

this was more common in Cape Town. Service users in Cape Town were much more likely to receive treatment for sexually transmitted infections, emergency contraception, and an antiemetic (as nausea is a common side effect of both emergency contraceptives and postexposure prophylaxis for HIV).

Of those who received antiretrovirals, $40 \quad(87 \%)$ in Thohoyandou said that they completed the course of zidovudine (AZT) and lamivudine (3TC) and nine (15\%) in Cape Town said they had completed a course of AZT alone. We were unable to determine whether pill taking was consistent. Most of the patients in Cape Town who did not finish the drugs stopped in

Table 3 Services received at health facility by women who had been raped and used the service, according to site. Figures are numbers (percentages) of participants unless stated otherwise

\begin{tabular}{|c|c|c|c|}
\hline & Cape Town $(n=78)$ & $\begin{array}{l}\text { Thohoyandou } \\
\qquad(\mathrm{n}=81)\end{array}$ & $P$ value \\
\hline Referred for counselling & $46(68)$ & $70(88)$ & 0.003 \\
\hline \multicolumn{4}{|l|}{ Referred to: } \\
\hline Clinic & $5(11)$ & 0 & \\
\hline NGO & $33(72)$ & $52(74)$ & \\
\hline Social worker & $6(13)$ & $18(26)$ & \\
\hline Other & $2(4)$ & 0 & \\
\hline $\begin{array}{l}\text { Able spontaneously to recall } \\
\text { receiving any medication }\end{array}$ & $65(96)$ & $67(84)$ & 0.17 \\
\hline \multicolumn{4}{|l|}{ Medication they recalled receiving: } \\
\hline STI medication & $29(71)$ & $18(29)$ & $<0.001$ \\
\hline Emergency contraception & $34(76)$ & $20(32)$ & $<0.001$ \\
\hline Antiemetic & $20(59)$ & $2(4)$ & $<0.001$ \\
\hline HIV prophylaxis & $45(88)$ & $45(70)$ & 0.021 \\
\hline Can't remember & 20 & 12 & $<0.001$ \\
\hline \multicolumn{4}{|c|}{ No of days patients recall taking HIV prophylaxis: } \\
\hline$<7$ & $25(40)$ & $1(2)$ & \\
\hline $8-14$ & $12(19)$ & $3(7)$ & \\
\hline $15-21$ & $13(21)$ & $2(4)$ & \\
\hline $22-27$ & $3(5)$ & 0 & \\
\hline Completed & $9(15)$ & $40(87)$ & $<0.001$ \\
\hline \multicolumn{4}{|l|}{ Reported side effects: } \\
\hline Headache & $20(32)$ & $25(39)$ & 0.389 \\
\hline Nausea & $25(39)$ & $28(44)$ & 0.590 \\
\hline Diarrhoea & $5(8)$ & $12(19)$ & 0.082 \\
\hline Rash & $4(6)$ & $9(14)$ & \\
\hline Tiredness & $23(45)$ & $25(56)$ & \\
\hline Received information on side effects & $36(55)$ & $34(51)$ & 0.661 \\
\hline Returned to facility & $62(91)$ & $45(57)$ & $<0.001$ \\
\hline \multicolumn{4}{|l|}{ How many times patients returned: } \\
\hline Once & $12(19)$ & $18(42)$ & \\
\hline $2-5$ & $39(62)$ & $20(47)$ & \\
\hline $6-12$ & $11(18)$ & $4(9)$ & \\
\hline
\end{tabular}

NGO=non-governmental organisation; STI=sexually transmitted infection. Data were missing in some cases.
Table 4 Number (percentage) of all participants (women who had been raped and those recruited from community) who agreed or strongly agreed with various statements

\begin{tabular}{|c|c|c|c|}
\hline & $\begin{array}{c}\text { Cape Town } \\
(\mathrm{n}=134)\end{array}$ & $\begin{array}{l}\text { Thohoyandou } \\
\quad(n=159)\end{array}$ & P value * $^{*}$ \\
\hline $\begin{array}{l}\text { I would not mind waiting } 3-4 \text { hours to see a health } \\
\text { worker who is sympathetic and will listen to me }\end{array}$ & $74(56)$ & 123 (79) & $<0.001$ \\
\hline $\begin{array}{l}\text { I would prefer not to be examined by a nurse } \\
\text { because nurses gossip about you }\end{array}$ & 53 (39) & 49 (31) & 0.162 \\
\hline $\begin{array}{l}\text { I want to be given medication that will prevent me } \\
\text { getting HIV but only if I can have it without } \\
\text { having an HIV test }\end{array}$ & 46 (34) & $20(13)$ & $<0.001$ \\
\hline $\begin{array}{l}\text { I would prefer a doctor to examine me after rape } \\
\text { because they are more skilled than nurses }\end{array}$ & $106(79)$ & $140(90)$ & 0.008 \\
\hline $\begin{array}{l}\text { I would prefer to travel to a hospital or clinic that is } \\
\text { far from where I live where I am sure no one will } \\
\text { know me }\end{array}$ & 68 (50) & 44 (28) & $<0.001$ \\
\hline $\begin{array}{l}\text { I would prefer a doctor/nurse who is a woman to } \\
\text { examine me }\end{array}$ & $102(76)$ & 107 (69) & 0.188 \\
\hline $\begin{array}{l}\text { I would like to receive counselling after rape even if } \\
\text { it means going back to the hospital }\end{array}$ & $123(91)$ & 154 (99) & 0.002 \\
\hline $\begin{array}{l}\text { I would prefer to receive all my HIV/AIDS } \\
\text { prevention medication at the first visit to the } \\
\text { hospital }\end{array}$ & 119 (88) & 147 (94) & 0.065 \\
\hline $\begin{array}{l}\text { I think that collecting samples from my private } \\
\text { parts and writing down my injuries will not help } \\
\text { the rapist being found guilty in court }\end{array}$ & 37 (27) & $15(10)$ & $<0.001$ \\
\hline The interview was easy or not too difficult & $93(69)$ & $146(94)$ & $<0.001$ \\
\hline
\end{tabular}

the first seven days. It is important to note that in Cape Town survivors had to return to the health service to get a weekly supply of drugs, which may explain why so many women did not complete the course of HIV prophylaxis.

Most women in Cape Town $(91 \%, \mathrm{n}=62)$ had returned at least once to the health facility, mainly for results of the HIV test. In Thohoyandou, 57\% (45) returned at least once. Women in Thohoyandou were visited at home by staff from the non-governmental organisation. The most common reason given for not returning was that the woman did not know that she had to, followed by not being able to get money for transport.

Table 4 shows the proportion of participants agreeing with statements on aspects of rape services. Table 5 shows results of the random effects probit models estimated in the discrete choice analysis. The availability of HIV prophylaxis was most important in determining choice of service, and prophylaxis even without an HIV test was preferred to no prophylaxis. The women, especially those from rural areas, strongly preferred to have an HIV test first. Skills and attitudes of the provider were also important, with a lack of understanding toward the patient being more negative in its influence on potential service use than additional training in counselling on top of a positive attitude. Many participants from both sites $(75$ (56\%) in Cape Town and $123(79 \%)$ in Thohoyandou) indicated that they would be willing to wait three to four hours to see a sensitive healthcare provider (table 4).

Most participants preferred a longer examination that might increase the possibility of the case going to court. This was especially the case among women from the rural area.

Participants favoured more returns to the facility (table 5), though the results shown in table 4 suggest that they wanted to return for counselling. Most women $(96 \%, \mathrm{n}=277)$ would return to the facility for counselling, while $8 \%(\mathrm{n}=27)$ indicated that they would prefer a drug regimen that required follow-up visits.

The overall model shows that participants did not make service preferences based on travel time. Urban interviewees preferred shorter travel times of less than 30 minutes, whereas 


\begin{tabular}{|c|c|c|c|c|c|c|}
\hline \multirow[b]{2}{*}{ Variable } & \multicolumn{2}{|c|}{ Across sites* } & \multicolumn{2}{|c|}{ Urban site† } & \multicolumn{2}{|c|}{ Rural site‡ } \\
\hline & Coeff $(95 \% \mathrm{CI})$ & $P$ value§ & Coeff $(95 \% \mathrm{CI})$ & P value§ & Coeff $(95 \% \mathrm{CI})$ & $P$ value§ \\
\hline Low travel time (<30 mins) & $\begin{array}{c}-0.02 \\
(-0.15 \text { to } 0.11)\end{array}$ & 0.782 & $\begin{array}{c}0.37 \\
(0.20 \text { to } 0.55)\end{array}$ & $<0.001$ & $\begin{array}{c}-0.62 \\
(-0.85 \text { to }-0.39)\end{array}$ & $<0.001$ \\
\hline High travel time (>3 hours) & $\begin{array}{c}-0.07 \\
(-0.20 \text { to } 0.07)\end{array}$ & 0.342 & $\begin{array}{c}0.17 \\
(-0.01 \text { to } 0.35)\end{array}$ & 0.076 & $\begin{array}{c}-0.28 \\
(-0.53 \text { to }-0.19)\end{array}$ & 0.036 \\
\hline PEP with HIV test & $\begin{array}{c}1.71 \\
(1.57 \text { to } 1.85) \\
\end{array}$ & $<0.001$ & $\begin{array}{c}1.52 \\
(1.35 \text { to } 1.70) \\
\end{array}$ & $<0.001$ & $\begin{array}{c}2.36 \\
\text { (2.05 to } 2.67) \\
\end{array}$ & $<0.001$ \\
\hline PEP without HIV test & $\begin{array}{c}0.70 \\
(0.59 \text { to } 0.82)\end{array}$ & $<0.001$ & $\begin{array}{c}1.05 \\
\text { (0.89 to } 1.22)\end{array}$ & $<0.001$ & $\begin{array}{c}0.33 \\
(0.16 \text { to } 0.49)\end{array}$ & $<0.001$ \\
\hline Returns to service & $\begin{array}{c}0.14 \\
(0.11 \text { to } 0.17) \\
\end{array}$ & $<0.001$ & $\begin{array}{c}0.06 \\
(0.02 \text { to } 0.09)\end{array}$ & 0.005 & $\begin{array}{c}0.36 \\
(0.29 \text { to } 0.42) \\
\end{array}$ & $<0.001$ \\
\hline Long examination & $\begin{array}{c}0.48 \\
(0.39 \text { to } 0.58)\end{array}$ & $<0.001$ & $\begin{array}{c}0.49 \\
(0.36 \text { to } 0.63)\end{array}$ & $<0.001$ & $\begin{array}{c}0.80 \\
(0.62 \text { to } 0.97)\end{array}$ & $<0.001$ \\
\hline Providers with no understanding & $\begin{array}{c}-0.75 \\
(-0.88 \text { to }-0.62)\end{array}$ & $<0.001$ & $\begin{array}{c}-0.32 \\
(-0.50 \text { to }-0.14)\end{array}$ & 0.001 & $\begin{array}{c}-0.98 \\
(-1.19 \text { to }-0.76)\end{array}$ & $<0.001$ \\
\hline $\begin{array}{l}\text { Providers with understanding and } \\
\text { training }\end{array}$ & $\begin{array}{c}0.56 \\
(0.40 \text { to } 0.73)\end{array}$ & $<0.001$ & $\begin{array}{c}0.59 \\
(0.37 \text { to } 0.81)\end{array}$ & $<0.001$ & $\begin{array}{c}0.89 \\
(0.58 \text { to } 1.20)\end{array}$ & $<0.001$ \\
\hline Constant & $\begin{array}{c}-0.13 \\
(-0.33 \text { to } 0.08)\end{array}$ & 0.239 & $\begin{array}{c}-0.97 \\
(-0.13 \text { to }-0.68)\end{array}$ & $<0.001$ & $\begin{array}{c}0.48 \\
(0.14 \text { to } 0.83)\end{array}$ & 0.006 \\
\hline
\end{tabular}

PEP=postexposure prophylaxis

*Likelihood ratio 1533.91, $\mathrm{P}<0.001\left(\chi^{2}\right)$; likelihood test of $r=0$ : 177.72, $\mathrm{P}<0.001\left(\chi^{2}\right)$.

†Likelihood ratio 512.77, $\mathrm{P}>0.001\left(\chi^{2}\right)$; likelihood test of $r=0$ : 67.91, $\mathrm{P}<0.001\left(\chi^{2}\right)$.

łLikelihood ratio 1304.87, $\mathrm{P}<0.001\left(\chi^{2}\right)$; likelihood test of $r=0: 39.87, \mathrm{P}<0.001\left(\chi^{2}\right)$.

$\S$ From random effects probit model. $P>$ absolute value of $z$.

those from rural areas did not mind travelling slightly longer, though not more than three hours.

\section{Discussion}

This is the first study of patients' preferences for attributes of services for people who have been raped. Our findings challenge some of the current assumptions of what is important to users of such services in South Africa. Respondents particularly valued the availability of HIV prophylaxis (with an HIV test) and having a sensitive healthcare provider who could provide counselling. Having a lengthy examination that could influence the legal outcome was also viewed as desirable, especially among rural women. This is surprising as research has suggested that examination is a major source of stress after rape. ${ }^{1}$

\section{Patient preferences regarding care}

Patients seem willing to trade off access to services (time travelled) for attributes such as counselling, rigour of examination, and HIV prophylaxis. It had been previously thought that access to services was a primary concern and this was reflected in efforts by the department of health to integrate services for people who have been raped into the core primary healthcare package. ${ }^{18}$ Research on factors associated with clinical quality of care ${ }^{3}$ shows that higher quality of care is associated with a larger case load, which is not found at the primary healthcare level for a relatively uncommon event such as rape. Our findings suggest this model of service provision is also inappropriate in terms of patient preferences.

Research on South African health services for people who have been raped has shown that there are gaps in service delivery. ${ }^{3}$ Reports from the women in our study who had used the service support this finding. All patients interviewed would have been eligible for treatment for sexually transmitted infections. However, fewer patients reported getting drugs for these infections than HIV prophylaxis. Patients seem often not to be given information on drugs and side effects in an effective way. Throughout the country rates of completion of HIV prophylaxis are low. ${ }^{19}$ The rates from Cape Town are similar to those in Gauteng Province, ${ }^{19}$ though rates in Thohoyandou are much higher. This is paradoxical in face of the high priority apparently given to HIV prevention. In Cape Town it may be because women have to return to the service weekly to collect drugs. Our findings suggest there was considerable attrition over the four weeks. Patients clearly prefer to get of all their HIV prophylaxis at the initial visit, as practised in Thohoyandou. Other factors that may influence completion of the course include the provision of antiemetics and information, neither of which was less prevalent in Cape Town. While provision of antiemetics may support adherence to treatment, our findings suggest that antiemetics alone do not result in better compliance. Factors that may be more important in Thohoyandhou were the home follow-up service provided by the non-governmental organisation and the provision of food supplements.

Contrary to fears expressed by the department of health and some commentators, the need to test for HIV before receiving HIV prophylaxis did not seem to deter women from attending services. There was no difference in the views of women who did and did not use the service. Our formative research indicated that the window period for the transmission of HIV was not well understood so testing positive for HIV immediately after rape was thought to indicate transmission during the rape. ${ }^{21}$ HIV infection after rape is perceived as less stigmatising than HIV acquired through other forms of sexual contact.22

The priority that participants place on receiving counselling highlights the need for a holistic service after rape. Other research shows that the mental health needs of patients are often the least well met. ${ }^{3}$ If services are to offer providers who are sensitive and can provide counselling, changes are needed in service provision and training, and this training should also deal with psychological support skills and providers' attitudes.

\section{Limitations}

The study had limitations. The two sites selected were to some extent unusual, which could have influenced findings. Both sites provide more support for patients than is typical within the public health system. The Cape Town site was a special care centre located within a hospital; it had a full time nurse to follow-up patients. At the time of the study there were 18 of these centres throughout the country. The Thohoyandou site had a non-governmental organisation running a trauma centre with the public hospital. They had a network of outreach workers in 


\section{What is already known on this topic}

Public health services for people who have been raped in South Africa are of varied quality and limited resources mean that the options for service provision are limited

\section{What this study adds}

After rape, women particularly valued the availability of HIV prophylaxis (with an HIV test) and having a sensitive healthcare provider who could provide counselling

Women were willing to trade off access to services (time travelled) for attributes such as counselling, rigour of examination, and HIV prophylaxis

the community and provided food to patients. Health providers in Cape Town did not approach every patient to participate in the study so we could not determine the refusal rate. As there were no significant differences between patients recruited through health facilities and members of the community, it is unlikely that there was a systematic bias in recruitment of patients.

Participants' preferences may have been influenced by what they had been exposed to in terms of service-for example, in Thohoyandou people are used to travelling to get to the hospital as there is only one hospital in the area. They may therefore be more accepting of this attribute. Other attributes that were not included in the analysis may have been important.

Our method of recruitment may have resulted in selection bias. Because of ethical considerations we could not randomly sample patients from hospital records. Patients who agreed to be contacted by a researcher may have systematically differed from those who refused. In addition, some community members refused to be interviewed, though this was rare.

\section{Conclusion}

In conclusion, women who have been raped are willing to travel to services that better meet their needs. They strongly value HIV prophylaxis, having an understanding health provider, and counselling. Our findings support the need for holistic rape services with medication systematically provided for sexually transmitted infection and prevention of pregnancy and information on known side effects. Support with adherence to treatment may also be valuable.

We thank the staff of the Thohoyandhou Victim Empowerment Progamme and Thutuzela at GF Jooste Hospital; Shanaaz Mathews and the fieldworkers at both sites; and Lehlohonolo Khotle for research assistance and data input.

Contributors: NJC participated in conception and design of the study, analysis and interpretation of data, and writing the article. DM participated in conception and design of the study and in writing the article; she conducted the discrete choice analysis. RKJ participated in conception and design of the study, interpretation of data, and critical revision of the article. LP-K and DNC participated in conception and design of the study, collection and interpretation of data. NJC is guarantor.

Funding: Unicef, Danish Government, and the South African Department of Health.
Competing interests: None declared.

Ethical approval: The University of Witwatersrand's health sciences committee for research on human subjects approved the study.

1 World Health Organization (WHO). Guidelines for medico-legal care for victims of sexual violence. Geneva: World Health Organization, 2003.

2 Jewkes R, Abrahams N. The epidemiology of rape and sexual coercion in South Africa: Jewkes R, Abrahams N. The epidemiology
an overview. Soc Sci Med 2002;55:1231-44.

3 Christofides NJ, Jewkes RK, Webster N, Penn-Kekana L, Abrahams, N, Martin LJ. "Other patients are really in need of medical attention"-the quality of health services for rape survivors in South Africa. Bull World Health Organ 2005;83:495-502.

4 Suffla S, Seedat M, Nascimento A. Evaluation of medico-legal services in Gauteng: implica tions for the development of best practices in the after-care of rape survivors. Pretoria: Institute for Social and Health Sciences and Centre for Peace Action, University of South Africa, 2001.

5 Human Right's Watch. South African violence against women and the medico-legal system. New York/Washington: Human Right's Watch, 1997.

6 Campbell R, Wasco SM, Ahrens CE, Sefl T, Barnes HE. Preventing the "second rape:" Rape survivors' experiences with community services providers. J Interpers Violence Rape survivors exper

7 Ericksen J, Dudley C, McIntosh G, Ritch L, Shumay S, Simpson M. Clients' experiences with a specialized sexual assault service. J Emerg Nurs 2002;28:86-90.

8 Resnick H, Acierno R, Holmes M, Dammeyer M, Kilpatrick D. Emergency evaluation and intervention with female victims of rape and other violence. J Clin Psychol 2000;56:1317-33.

9 McCauley J, Yurk RA, Jenckes MW, Ford DE. Inside Pandora's box: abused women's experiences with clinicians and health services. J Gen Intern Med 1998;13:549-55.

10 Department of Health. Sexual assault clinical management guidelines. Pretoria: Department of Health, 2003

11 Garcia-Moreno C. Dilemmas and opportunities for an appropriate health-service response to violence against women. Lancet 2002;359:1509-14.

12 Tesler H, Zweifel P. Measuring willingness-to-pay for risk reduction: an application of conjoint analysis. Health Econ 2002;11:129-39.

13 Phillips K, Maddala T. Reed Johnson. F Measuring preferences for health care interventions using conjoint analysis: an application to HIV testing. Health Serv Res 2002;37:1681-705

14 Lancsar E, Savage S. Deriving welfare measures from discrete choice experiments: inconsistency between current methods and random utility and welfare theory. Health Econ 2004;13:901-7.

15 Hanson K, McPacke B, Nakamba P, Archard L. Preferences for hospital quality in Zambia: results from a discrete choice experiment. Health Econ 2005;14:687-701.

16 Ryan M, Farrar S. Using conjoint analysis to elicit preferences for health care. BMJ 2000:320:1530-3.

17 Jewkes R, Nduna M, Levin J, Jama N, Dunkle K, Khuzwayo N, et al. A cluster randomised controlled trial to determine the effectiveness of Stepping Stones in preventing HIV infections and promoting safer sexual behaviour amongst youth in the venting HIV infections and promoting safer sexual behaviour amongst youth in the
rural Eastern Cape, South Africa: trial design, methods and baseline findings. Trop Med Int Health (in press).

18 Department of Health (DOH). The primary health care package for South Africa-a set of norms and standards. www.doh.gov.za/docs/policy-f.html (accessed Nov 2005).

19 Vetten L, Haffejee S. Factors affecting adherence to post-exposure prophylaxis in the aftermath of sexual assault: key findings from seven sites in Gauteng Province. Johannesburg, South Africa: Centre for the Study of Violence and Reconciliation, 2004.

20 Kim JC, Martin LJ, Denny L. Rape and HIV post-exposure prophylaxis: addressing the dual epidemics in South Africa. Reprod Health Matters 2003;11:101-12.

21 Christofides NJ, Jewkes RK, Muirhead D, Penn-Kekana L, Conco DN. Including PEP into post sexual assault health services in South Africa: costs and cost effectiveness of user preferred post sexual assault health services in South Africa: costs and cost effectiveness of user p

22 Deacon H, Stephney I, Prosalendis S. The social context and history of stigma in South Africa. Second African Conference on the Social Aspects of HIV/AIDS. Cape Town, May 2004:9-12.

(Accepted 4 October 2005)

doi $10.1136 /$ bmj.38664.482060.55

Gender and Health Research Unit, Medical Research Council, Private Bag x385 Pretoria 0001, South Africa, and School of Public Health, University of

Witwatersrand, Johannesburg, 0001, South Africa

NJ Christofides specialist scientist

$\mathrm{R} \mathrm{K}$ Jewkes director

Aurum Health Research, PO Box 61587 Marshalltown, 2107, South Africa D Muirhead health economist

Centre for Health Policy, School of Public Health, University of Witwatersrand, Johannesburg, 0001, South Africa

L Penn-Kekana researcher

Women's Health Project, School of Public Health, University of Witwatersrand

D N Conco programme manager

Correspondence to: NJ Christofides nicola.chris@mrc.ac.za 